\title{
Monitoring of Transmission Line Wildfires Using Satellite Remote Sensing
}

\author{
Xiao-Ran $\mathrm{YI}^{1 \text {,a }}$, En-Zhe ZHOU ${ }^{1}$,Li YE, ${ }^{2, b,}$, ,Shuang-Yu DU1 ,Zhan-Qing YU ${ }^{2}$ \\ ${ }^{1}$ Electric Power Research Institute of Guangdong Power Grid Co., Ltd., Guangzhou Guangdong \\ 510080, China \\ ${ }^{2}$ Tsinghua University, Beijing 100084, China \\ a yayaceee@163.com, b64278287@qq.com
}

\begin{abstract}
Keywords: Satellite Remote Sensing, Wildfire of Transmission Line, Wildfire Monitoring, Fire Spot Screening, Fuzzy Synthetic Evaluation Method.

Abstract. Wildfires can cause transmission lines to trip, which can prove difficult to reclose successfully. Using satellite remote sensing technology to monitor wildfires can alert the power sector to potential damage. However, wildfires along transmission lines may have a small burned area and may spread rapidly. In addition, false alarms and missing alarms often happen in real-world situations. Monitoring, therefore, needs high spatial and temporal resolution satellite data. To address this problem, this paper identifies the monitoring index requirements for satellite data based on the characteristics of transmission line wildfires. Using historical fault information from wildfires for transmission lines in Guangdong province, China, this paper considered the influence of each impact factor, combining a fuzzy synthetic evaluation method and trapezoidal method to establish a model for wildfire screening. The proposed method can distinguish true and false fire spots. The accuracy of the model was verified by using examples, and the model was able to meet the accuracy requirements for engineering applications. Finally, this paper suggested a three-level wildfire alarm system for transmission lines according to operating experience, providing guidance for on site management.
\end{abstract}

\section{Introduction}

With the development of new power grids and a rapid increase in demand for electricity, highcapacity and long-distance transmission lines inevitably cross forested areas. Wildfires along transmission lines cause the lines to trip which seriously affects the safe and stable operation of the power grid. Statistics showed that transmission lines in the Guangdong power grid were tripped 142 times from 2001 to 2016. Wildfires along transmission lines have a rapid development speed. Once the line trips, it is often difficult to reclose successfully. Thus, understanding how to monitor wildfires along transmission lines based on various technologies is significant to develop graded fire alarms. This research will contribute to the operation and maintenance technology of lines in fire situations, and it will contribute to the safety of transmission line operation, improving the reliability of power supplies.

At present, meteorological departments can easily monitor large areas of forest fires using satellite remote sensing technology[1]. Since a catastrophic forest fire in Greater Khingan on May 6, 1987, China has established comprehensive forest fire monitoring using polar-orbit meteorological satellites. The weather and forestry bureaus have built a sophisticated satellite remote sensing system to monitor forest fires. LIU Yujie elucidated the algorithm principle of monitoring fire with EOS/MODIS satellite data[2]. LIU Cheng explained how to solve sub-pixel fire area and brightness temperature from meteorological satellites[3]. Reference [4] proposed a three-channel synthesis method based on remote sensing exploration to identify the fire, but it was of low precision, only suitable for qualitative monitoring of large area of forest fires. References [5,6] discussed a contextual fire spot discriminated method which was applicable to environmental satellites, but environmental satellites cannot meet the real-time monitoring requirements of transmission line wildfires at small scales because of their low spatial resolution. References [7,8] used satellite remote sensing fire information, provided by the Meteorological Department, to monitor transmission line wildfires. However, due to the limitations of remote sensing technology and the influence of solar flares or clouds, the issue of false 
alarms and missing alarms was problematic. To solve the problems outlined above, this paper combined a fuzzy synthetic evaluation method with a trapezoidal method to establish a model for wildfire screening. The model aimed to identify the differences between areas and time intervals. It considered the importance of each impact factor to the model, based on the satellite remote sensing fire information, to release accurate alarm information and to help power company personnel make the right decisions.

\section{Satellite Remote Sensing Technology}

Satellite remote sensing uses spectral information collected by a sensor distant from the target to acquire characteristic information on the target object. These data can then be extracted, judged, processed and analyzed [9].

\subsection{Wildfire monitoring principles}

Wein's displacement law[10] describes the quantitative relationship between an object's radiation peak wavelength and temperature. It can be expressed as:

$$
\lambda_{\max }=A / T
$$

Where A is constant, its value is $2898 \mu \mathrm{m} / \mathrm{K}$; blackbody temperature $T$ is inversely proportional to radiation wavelength $\lambda_{\max }$.

\subsection{Satellite remote sensing index for analyzing fire disasters in power systems}

Temporal resolution refers to the minimum time of repeat observations of satellite sensors[11]. Operational experience shows that fire more than $3 \mathrm{~km}$ from the transmission line will not affect systems. Closer than that, wildfire can cause transmission line tripping within a few to dozens of minutes. The propagation velocity of fire is about $2 \mathrm{~m} / \mathrm{s}-5 \mathrm{~m} / \mathrm{s}$. This paper chose 15 minutes as desired temporal resolution for monitoring power systems. This will ensure that wildfire cannot affect lines between the satellite monitoring interval.

Spatial resolution refers to the minimum angle or linear distance measurement between two targets which can be distinguished by sensors. According to engineering experience, the unit distance of existing transmission line fire alarms is $1 \mathrm{~km}$. In order to meet alarm requirements, spatial resolution should at least reach this standard of resolution. In this case, it can provide definite information on the fire alarm level.

Monitoring is mainly aimed at the transmission lines of the southern power grid. Existing satellite indicators have been able to achieve the monitoring requirements outlined above (see Table 1).

Table 1 Satellite remote sensing index set for analyzing fire disasters in power systems

\begin{tabular}{ll}
\hline Index & Parameter range \\
\hline $\begin{array}{l}\text { Temporal } \\
\text { resolution }\end{array}$ & $15 \mathrm{~min}$ \\
\hline Spatial resolution & $1 \mathrm{~km}$ \\
\hline Sensor types & $\begin{array}{l}\text { MODIS、AVHRR、CCD、IRS, et } \\
\text { al. }\end{array}$ \\
\hline Sweep length & $2300 \mathrm{~km}$ \\
\hline Scan period & $100 \mathrm{~min}$ \\
\hline Monitoring scope & Global/Local \\
\hline
\end{tabular}

\section{Fire Identification and Confidence Estimation}

This paper used meteorological factors, human factors and other fire impact factors to build a fire screening model and estimate the confidence of fire information from the model. This will reduce misjudgments in wildfire situations. 


\subsection{Quantifying the risk level and probability of fire}

According to the National Forest Fire Level and the Forest Fire-Danger Weather Ratings specification, fire risk evaluation can be divided into five levels, quantified in Table 2.

Table 2 Quantifying the risk level and probability of fire

\begin{tabular}{ccc}
\hline $\begin{array}{c}\text { fire danger } \\
\text { class }\end{array}$ & $\begin{array}{c}\text { combustion } \\
\text { possibility }\end{array}$ & $\begin{array}{c}\text { confidence factor of } \\
\text { fire }\end{array}$ \\
\hline 1 level & Can't burn & $<9.87 \%$ \\
2 level & Be difficult to burn & $9.87 \% \sim 19.74 \%$ \\
3 level & Can burn & $19.74 \% \sim 39.55 \%$ \\
4 level & Be easy to burn & $39.55 \% \sim 79.17 \%$ \\
5 level & Extremely & $>79.17 \%$ \\
& flammable & \\
\hline
\end{tabular}

According to the history of fault information and operational experience, the model deduced whether the hot spot shown in satellite remote sensing was a real fire spot using a confidence threshold. The specific divisions are shown in Table 3:

Table 3 The relationship between confidence threshold and fire spot determination

\begin{tabular}{cc}
\hline determination & $\begin{array}{c}\text { confidence factor of } \\
\text { fire }\end{array}$ \\
\hline $\mathrm{A}$ (true fire) & $>39.55 \%$ \\
$\mathrm{~B}$ (false fire) & $\leq 39.55 \%$ \\
\hline
\end{tabular}

Based on the wildfire fault case library of Guangdong from 2001 to 2016, this paper synthesized factors such as daily maximum temperature $\left({ }^{\circ} \mathrm{C}\right)$ minimum relative humidity $(\%)$ and average wind velocity $(\mathrm{m} / \mathrm{s})$. Taking the maximum and minimum values as the fluctuation range, the model built an equal interval danger meter which conformed to meteorological conditions in Guangdong. This is shown in Table 4.

Table 4 Danger meter for Guangdong Power Grid

\begin{tabular}{lccccc}
\hline & 1 level & 2 level & 3 level & 4 level & 5 level \\
\hline $\begin{array}{l}\text { daily maximum temperature } \\
\left({ }^{\circ} \mathrm{C}\right)\end{array}$ & $\leq 18$ & $18 \sim 23$ & $23 \sim 28$ & $28 \sim 33$ & $\geq 33$ \\
$\begin{array}{c}\text { minimum relative humidity } \\
(\%)\end{array}$ & $\geq 62.4$ & $62.4 \sim 49.8$ & $49.8 \sim 37.2$ & $37.2 \sim 24.6$ & $\leq 24.6$ \\
\begin{tabular}{l} 
average wind velocity $(\mathrm{m} / \mathrm{s})$ \\
\hline
\end{tabular} & $\leq 1.2$ & $1.2 \sim 2.4$ & $2.4 \sim 3.6$ & $3.6 \sim 4.8$ & $\geq 4.8$ \\
\hline
\end{tabular}

\subsection{Calculation of fire confidence intervals based on fuzzy synthetic evaluation}

The fuzzy synthetic evaluation method includes factor set $X$, decision set $U$ and fuzzy matrix transformation $R$. Where:

Factor set $X=\left\{x_{1}, x_{2}, \cdots \cdots, x_{n}\right\}$

Decision set $U=\left\{u_{1}, u_{2}, \cdots \cdots, u_{m}\right\}$

Fuzzy matrix transformation $R$ representing the mapping of $X$ to $U$.

$$
R=\left[\begin{array}{ccc}
r_{11} & A & r_{1 m} \\
M & A & M \\
r_{n 1} & A & r_{n m}
\end{array}\right]
$$

The fire danger was divided into $m$ levels, and the factor's correction coefficient was a fuzzy subset $A=\left\{a_{1}, a_{2}, \cdots \cdots, a_{n}\right\}$ (also called the weight) of $X . B=\left\{b_{1}, b_{2}, \cdots \cdots, b_{m}\right\}$ is the comprehensive 
subordinated vector of fire risk. According to the maximum membership principle, once the fire danger rating can be determined then the confidence factor of fire can be found.

(1) Determining factor sets

According to the wildfire fault case library of Guangdong from 2001 to 2016, fires were often caused by human activities such as field burning, ancestor worship and other festivals. Accordingly, this paper selected a range of natural and anthropogenic impact factors as follows:

$$
X=(R, T, H, W, K)
$$

Where $R$ is daily precipitation, $T$ is daily maximum temperature, $H$ is daily minimum relative humidity, $W$ is daily average wind velocity, and $K$ is anthropogenic factor.

We used the hierarchical analysis software, Yaahp, to obtain the weight of each impact factor, as shown as Fig. 1.

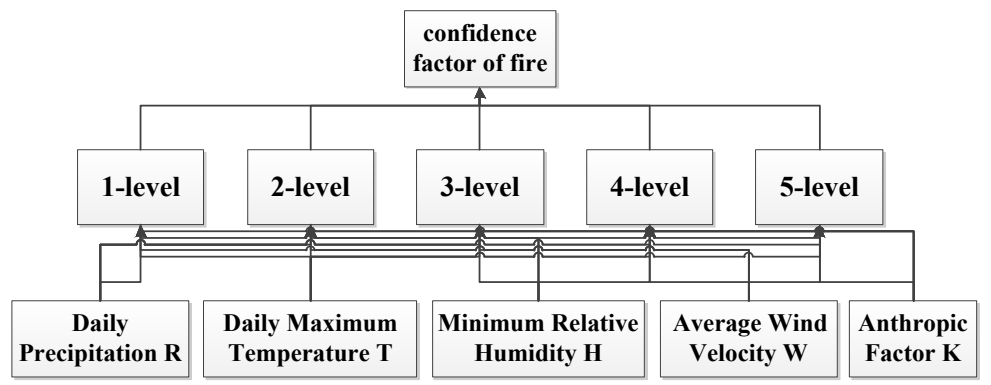

Fig. 1 Model solution to establish the weight of each factor

The weight was $A=\left(a_{R}, a_{T}, a_{H}, a_{W}, a_{K}\right)=(0.05,0.2,0.2,0.15,0.4)$, where $a_{R}, a_{T}, a_{H}, a_{W}, a_{K}$ is the weight of each factor.

(2) Decision set

This paper divided fire risk into 5 levels, according to the decision criterion shown below.

$U=(1$ level, 2 level, 3 level, 4 level, 5 level)

(3) Membership function

The membership function $\mathrm{R}$ of the factor was set to the decision criterion mark as shown below.

$$
\mathrm{R}=\left[\begin{array}{ccccc}
R_{1} & R_{2} & R_{3} & R_{4} & R_{5} \\
T_{1} & T_{2} & T_{3} & T_{4} & T_{5} \\
H_{1} & H_{2} & H_{3} & H_{4} & H_{5} \\
W_{1} & W_{2} & W_{3} & W_{4} & W_{5} \\
K_{1} & K_{2} & K_{3} & K_{4} & K_{5}
\end{array}\right]
$$

$T, H$ and $W$ are continuous functions. Based on the fire fault information and danger meter for Guangdong, their membership functions were solved by a trapezoidal method, as follows.

$$
T_{1}=\left\{\begin{array}{cc}
1 & t \leq 18 \\
\frac{23-t}{5} & 18<t \leq 23 \\
0 & \text { others }
\end{array} \quad(5) \quad T_{2}=\left\{\begin{array}{cc}
\frac{t-13}{5} & 13 \leq t<18 \\
1 & 18<t \leq 23 \\
\frac{28-t}{5} & 23<t \leq 28 \\
0 & \text { others }
\end{array} \quad(6) \quad T_{3}=\left\{\begin{array}{cc}
\frac{t-18}{5} & 18 \leq t<23 \\
1 & 23<t \leq 28 \\
\frac{33-t}{5} & 28<t \leq 33 \\
0 & \text { others }
\end{array}\right.\right.\right.
$$

$T_{4}=\left\{\begin{array}{cc}\frac{t-23}{5} & 23 \leq t<28 \\ 1 & 28<t \leq 33 \\ \frac{38-t}{5} & 33<t \leq 38 \\ 0 & \text { others }\end{array}\right.$

$$
\text { (8) } T_{5}=\left\{\begin{array}{cc}
0 & t \leq 28 \\
\frac{t-28}{5} & 28 \leq t<33 \\
1 & \text { others }
\end{array}\right.
$$

$$
H_{1}=\left\{\begin{array}{cc}
1 & h \geq 62.4 \\
\frac{h-49.8}{12.6} & 49.8 \leq h<62.4 \\
0 & \text { others }
\end{array}\right.
$$

$$
H_{2}=\left\{\begin{array}{cc}
\frac{h-37.2}{12.6} & 37.2 \leq h<49.8 \\
1 & 49.8<h \leq 62.4 \\
\frac{75-h}{12.6} & 62.4<h \leq 75 \\
0 & \text { others }
\end{array}\right.
$$




$$
\begin{aligned}
& H_{3}=\left\{\begin{array}{cc}
\frac{h-24.6}{12.6} & 24.6 \leq h<37.2 \\
1 & 37.2<h \leq 49.8 \\
\frac{62.4-h}{12.6} & 49.8<h \leq 62.4 \\
0 & \text { others }
\end{array} \quad(12) \quad H_{4}=\left\{\begin{array}{cc}
\frac{h-12}{12.6} & 12 \leq h<24.6 \\
1 & 24.6<h \leq 37.2 \\
\frac{49.8-h}{12.6} & 37.2<h \leq 49.8 \\
0 & \text { others }
\end{array}\right.\right. \\
& H_{5}=\left\{\begin{array}{cc}
1 & h \leq 24.6 \\
\frac{37.2-h}{12.6} & 24.6<h \leq 37.2 \\
0 & \text { others }
\end{array}\right. \\
& W_{1}=\left\{\begin{array}{cc}
1 & w \leq 1.2 \\
\frac{2.4-w}{1.2} & 1.2<w \leq 2.4 \\
0 & \text { others }
\end{array}\right. \\
& W_{3}=\left\{\begin{array}{cc}
\frac{w-1.2}{1.2} & 1.2 \leq w<2.4 \\
1 & 2.4<w \leq 3.6 \\
\frac{4.8-w}{1.2} & 3.6<w \leq 4.8 \\
0 & \text { others }
\end{array}\right. \\
& W_{5}=\left\{\begin{array}{cc}
0 & w \leq 3.6 \\
\frac{w-3.6}{1.2} & 3.6<w \leq 4.8 \\
1 & \text { others }
\end{array}\right. \\
& W_{2}=\left\{\begin{array}{cc}
\frac{w}{1.2} & 0 \leq w<1.2 \\
1 & 1.2<w \leq 2.4 \\
\frac{3.6-w}{1.2} & 2.4<w \leq 3.6 \\
0 & \text { others }
\end{array}\right. \\
& W_{4}=\left\{\begin{array}{cc}
\frac{w-2.4}{1.2} & 2.4 \leq w<3.6 \\
1 & 3.6<w \leq 4.8 \\
\frac{6-w}{1.2} & 4.8<w \leq 6 \\
0 & \text { others }
\end{array}\right.
\end{aligned}
$$

$R$ and $K$ are discrete variables. It can be seen from the study of historical fire data, that more than $85 \%$ of wildfires occurred on precipitation-free days and more than $99 \%$ of wildfires occurred when 24 h-precipitation was less than $8 \mathrm{~mm}$. When $R>8 \mathrm{~mm}$, there was almost no fire. Human activities such as ancestor worship, field burning are related to months, so the model explained the influence of artificial factors from a monthly perspective.

$$
\begin{aligned}
& R_{1}=\left\{\begin{array}{cc}
1 & r \geq 8 \\
0.8 & 0<r<8 \\
0.2 & r=0
\end{array}\right. \\
& R_{4}=\left\{\begin{array}{cc}
0.4 & r \geq 8 \\
0.32 & 0<r<8 \\
0.8 & r=0
\end{array}\right. \\
& K_{1}=\left\{\begin{array}{cc}
0.2 & k=1,2,3,4 \\
1 & k=5,6,7,8 \\
0.4 & k=9,10,11,12
\end{array}\right. \\
& K_{3}=\left\{\begin{array}{cc}
0.6 & k=1,2,3,4 \\
0.6 & k=5,6,7,8 \\
0.6 & k=9,10,11,12
\end{array}\right. \\
& K_{5}=\left\{\begin{array}{cc}
1 & k=1,2,3,4 \\
0.2 & k=5,6,7,8 \\
0.8 & k=9,10,11,12
\end{array}\right. \\
& R_{2}=\left\{\begin{array}{cc}
0.8 & r \geq 8 \\
0.64 & 0<r<8 \\
0.6 & r=0
\end{array}\right. \\
& R_{5}=\left\{\begin{array}{cc}
0.2 & r \geq 8 \\
0.16 & 0<r<8 \\
1 & r=0
\end{array}\right. \\
& \text { (21) } R_{3}=\left\{\begin{array}{cc}
0.6 & r \geq 8 \\
0.48 & 0<r<8 \\
0.6 & r=0
\end{array} \quad(22)\right. \\
& K_{2}=\left\{\begin{array}{cc}
0.4 & k=1,2,3,4 \\
0.8 & k=5,6,7,8 \\
0.5 & k=9,10,11,12
\end{array}\right. \\
& K_{4}=\left\{\begin{array}{cc}
0.8 & k=1,2,3,4 \\
0.4 & k=5,6,7,8 \\
0.7 & k=9,10,11,12
\end{array}\right.
\end{aligned}
$$

(4) Subjection degree of each factor to the fire decision set

The subjection degree of each factor to the fire decision set is as follows.

$$
M=\left[\begin{array}{lllll}
M_{1} & M_{2} & M_{3} & M_{4} & M_{5}
\end{array}\right]
$$

Where $M_{i}=\left(R_{i}, T_{i}, H_{i}, W_{i}, K_{i}\right)^{\mathrm{T}}$, means the subjection degree at the $i$-level confidence coefficient of fire spots.

Considering the importance of all the factors, $B$ is obtained as follows by the weight.

$$
B=\left[\begin{array}{lllll}
b_{1} & b_{2} & b_{3} & b_{4} & b_{5}
\end{array}\right]=A \times M
$$

where $b_{i}=a_{R} \times R_{i}+a_{T} \times T_{i}+a_{H} \times H_{i}+a_{W} \times W_{i}+a_{K} \times K_{i}, i=1,2,3,4,5$.

After running the model, the confidence coefficient could be used to judge true and false fire spots. In order to meet the needs of the assessment, this paper chose the maximum confidence coefficient 
of the corresponding fire danger class as the confidence coefficient.

\subsection{Application Example}

We used historical fire failure data in Guangdong to verify the screening model, as shown below in Table 5.

Table 5: Satellite remote sensing hot spot information

\begin{tabular}{ccccccc}
\hline $\begin{array}{c}\text { power } \\
\text { supply } \\
\text { bureau }\end{array}$ & $\begin{array}{c}\text { monitor } \\
\text { ing } \\
\text { time }\end{array}$ & satellite & affected tower & \multicolumn{2}{c}{$\begin{array}{c}\text { Coordinate of fire } \\
\text { spot }\end{array}$} & $\begin{array}{c}\text { If there } \\
\text { is a fire } \\
\text { limeitude }\end{array}$ \\
\hline Shaoguan & $2015-$ & TERRA & 220kV QU- & 113.7215 & 24.493 & Yes \\
& $12-18$ & & WENG Line A & & 7 & \\
& $11: 55$ & & $(\# 54-\# 59)$ & & & \\
\hline
\end{tabular}

According to the data from the meteorological website, daily precipitation, daily maximum temperature, minimum relative humidity, average wind velocity and anthropogenic factors were used to calculate the confidence coefficient, as shown.

$$
\begin{gathered}
X=(0,13.4,30,2.2,12) \\
b_{1}=0.05 \times 0.2+0.2 \times 1+0.2 \times 0+0.15 \times 1 / 6+0.4 \times 0.4=0.395 \\
b_{2}=0.05 \times 0.6+0.2 \times 0.08+0.2 \times 0+0.15 \times 1+0.4 \times 0.5=0.396 \\
b_{3}=0.05 \times 0.6+0.2 \times 0+0.2 \times 3 / 7+0.15 \times 5 / 6+0.4 \times 0.6=0.481 \\
b_{4}=0.05 \times 0.8+0.2 \times 0+0.2 \times 1+0.15 \times 0+0.4 \times 0.7=0.52 \\
b_{5}=0.05 \times 1+0.2 \times 0+0.2 \times 4 / 7+0.15 \times 0+0.4 \times 0.8=0.326
\end{gathered}
$$

It can be seen from the above calculation, that $b_{4}$ was the maximum. On the basis of Table 2 , the confidence coefficient of transmission line wildfire was $79.17 \%$. This reflected real fires which was consistent with the actual situation.

Table 6: Satellite remote sensing hot spot information

\begin{tabular}{lllllll}
\hline $\begin{array}{l}\text { power } \\
\text { supply } \\
\text { bureau }\end{array}$ & $\begin{array}{l}\text { monitorin } \\
\text { g time }\end{array}$ & $\begin{array}{l}\text { sat } \\
\text { elli } \\
\text { te }\end{array}$ & affected tower & $\begin{array}{c}\text { Coordinate of } \\
\text { fire spot } \\
\text { longit latitude } \\
\text { ude }\end{array}$ & $\begin{array}{l}\text { If there is } \\
\text { a fire }\end{array}$ \\
\hline Shaoguan & $2016 / 2 / 8$ & FY & 500kVPING-QU Line & 113.1 & 25.0051 & Yes \\
& $14: 57: 00$ & 3B & $\begin{array}{l}(90-103), 220 k V G U A \\
\text { N-TONG Line(69-94) }\end{array}$ & 009 & \\
& & & & & \\
\hline
\end{tabular}

The calculation procedures are shown as follows.

$$
\begin{gathered}
X=(0,20.9,17,2.5,2) \\
b_{1}=0.05 \times 0.2+0.2 \times 0.42+0.2 \times 0+0.15 \times 0+0.4 \times 0.2=0.174 \\
b_{2}=0.05 \times 0.6+0.2 \times 1+0.2 \times 0+0.15 \times 11 / 12+0.4 \times 0.4=0.528 \\
b_{3}=0.05 \times 0.6+0.2 \times 0.58+0.2 \times 0+0.15 \times 1+0.4 \times 0.6=0.536 \\
b_{4}=0.05 \times 0.8+0.2 \times 0+0.2 \times 25 / 63+0.15 \times 1 / 12+0.4 \times 0.8=0.452 \\
b_{5}=0.05 \times 1+0.2 \times 0+0.2 \times 1+0.15 \times 0+0.4 \times 1=0.65
\end{gathered}
$$

It can be seen from the above calculation that $b_{5}$ is the maximum. The confidence coefficient was greater than $79.17 \%$. This reflected real fire which was consistent with the actual situation. 
Table 7: Satellite remote sensing hot spot information

\begin{tabular}{lllllll}
\hline $\begin{array}{l}\text { power } \\
\text { supply } \\
\text { bureau }\end{array}$ & $\begin{array}{l}\text { monit } \\
\text { oring } \\
\text { time }\end{array}$ & satellite & affected tower & \multicolumn{2}{c}{$\begin{array}{c}\text { Coordinate of fire } \\
\text { spot } \\
\text { longitu latitude } \\
\text { de }\end{array}$} & $\begin{array}{l}\text { If there } \\
\text { is a fire }\end{array}$ \\
\hline Shaoguan & $2016 /$ & AQUA & 500kVPING-QU & 113.10 & 25.024 & No \\
& $2 / 8$ & & Line (93-103,108- & 78 & 6 & \\
& $14: 35$ & & 114), 220kVGUAN- & & \\
& $: 00$ & & TONG Line (83-101) & & \\
\hline
\end{tabular}

According to the data from the meteorological website, the specific calculation procedures were as follows.

$$
\begin{gathered}
X=(0,23.2,26,2.6,2) \\
b_{1}=0.09 ; \quad b_{2}=0.507 ; \quad b_{3}=0.642 ; \quad b_{4}=0.593 ; \quad b_{5}=0.628
\end{gathered}
$$

Here, $b_{3}$ was the maximum and the confidence coefficient was $39.55 \%$. There was no fire around the line, proving that the model can eliminate false alarms from satellite data.

\section{Fire Alarms for Transmission Lines}

Many transmission lines and large areas of fire will result in large computation needs. This paper used an optimization algorithm which only calculated the distance of the tower which was nearest to the fire spot. The theory is shown in Fig. 2. Using the line distribution map, the model first searched for the nearest tower in the grid. If there was no tower in the grid, it then extended the search into the neighboring grid, until it found the nearest tower. Then the distance of the tower from the fire was calculated. If this was less than the fire alarm threshold values, the power sector should release alarm information and alert staff to handle the problem.

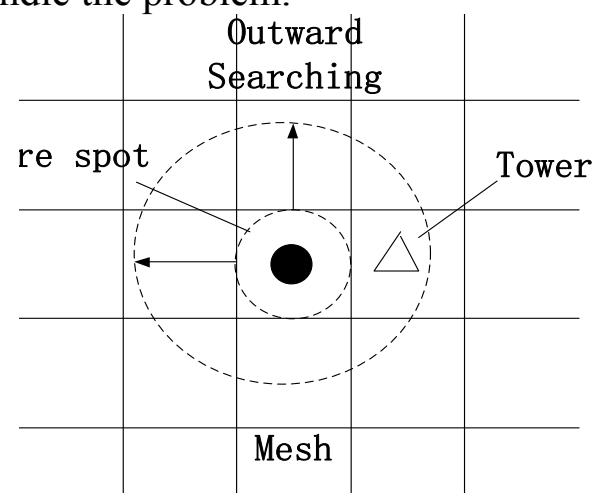

Fig. 2 Calculation diagram of distance between fire spot with tower

The detailed procedures to solve the distances are as follows. (1) Establish the distributio $\mathrm{n}$ map of transmission lines on a grid. (2) Seek the fire spot belonging to a grid cell, and find the nearest tower. (3) Solve the distance from the fire to the nearest tower using a sp herical distance formula $\mathrm{d}\left(\mathrm{x}_{1}, \mathrm{y}_{1}, \mathrm{x}_{2}, \mathrm{y}_{2}\right)=\mathrm{R} \times \arccos \left(\sin \left(\mathrm{x}_{1}\right) \times \sin \left(\mathrm{x}_{2}\right)+\cos \left(\mathrm{x}_{1}\right) \times \cos \left(\mathrm{x}_{2}\right) \times \cos \left(\mathrm{y}_{1}-\mathrm{y}\right.\right.$ 2)), where $\mathrm{R}$ is the Earth's radius. (4) According to the distance, the power section can esti mate the alarm level and release an alarm message. On the basis of previous operational ex perience, the range of the alarm distance is as follows.

$$
\left\{\begin{array}{cl}
d<500 \mathrm{~m} & \text { 1-level fire alarm } \\
500 \mathrm{~m} \leq d<1500 \mathrm{~m} & \text { 2-level fire alarm } \\
1500 \mathrm{~m} \leq d<3000 \mathrm{~m} & \text { 3-level fire alarm }
\end{array}\right.
$$

\section{Conclusion}


1) For power system fire disasters, this paper proposed the following satellite indexes: temporal resolution of $15 \mathrm{~min}$; spatial resolution of $1 \mathrm{~km}$; sweep length $2300 \mathrm{~km}$ and scan period of $100 \mathrm{~min}$.

2) In order to improve monitoring precision, this paper used a screening model to discriminate true points from false points.

3) Based on historical fire data from Guangdong, the results verified the accuracy of the fire screening model, which proved to meet the requirements for existing transmission line wildfire monitoring.

4) A three-stage alarm for transmission line fires was devised according to the distance of lines to the fire spot, and this distance was calculated by an optimization algorithm. This paper laid the foundation for improving the operation and maintenance of transmission lines in the event of wildfires.

\section{References}

[1] FAN Tianxi. The Estimation of Sub-pixel Fire Temperature and Area [C]. Remote Sensing Research Conferennce Prceeding of Environmental Monitoring and Agricultural Output Assessment. Beijing: PekingUniversity Press, 1991,165-170.

[2] LIU Yujie, YANG Zhongdong. Dispose Principle and Algorithm of MODIS Remote Sensing Information [M].Beijing: Science Press,2001,260-276.

[3] LIU Cheng, LI Yajun, ZHAO Changhai, et al. The Method of Evaluating Sub-pixel Size and Temperature of Fire Spot in AVHRR Data [J]. Journal of Applied Meteorological Science,2004,15(3),273-280.

[4] YE Liping, CHEN Xiyang, HE Zilan, et al. Present situation of forest fire early warning technology used for transmission line [J].Power System Protection and Control,2014,,42(6):145-153.

[5] Wang S D,Miao L L,Peng G X.An improved algorithm for forest fire detection using HJ data[J]. Procedia Environmental Science,2012,13:140-150.

[6] Giglio L,Csiszar I,Jeffrey T,et al.Active fire detection and characterization with the advanced spaceborne thermal emission and reflection radiometer (ASTER) [J].Remote Sensing of Environment,2008,112(6):3005-3063.

[7] ZHU Shiyang, DENG Yurong. Research and Application of Wildfire Monitoring Technology for Transmission Line Corridor[J]. Guangxi Electric Power,2013,36(3):25-27.

[8] LIANG Yun, LI Zhe, QU Yanyan, et al. The Polar Orbit Meteorological Satellite and Its Application in Monitoring Mountain Fire for Transmission Line[J].HENAN SCIENCE, 2013,31(10):1664-1667.

[9] JIANG Weiguo. Remote Sensing Satellite Introduction [M].Beijing: Science Press,2015:22-38.

[10]WANG Lina, SUN Dan. The Application of GIS and remote sensing technology in Heilongiiang Forest Fire Monitoring and Decision Support[J]. Forest Fire Monitoring, 2006(2): 23-25.

[11]GUO Pengbo. Forest-Fire Monitoring Principles and Technology through Satellite[J].Shaanxi Forest Science and Technology, 2004, 32(2): 35-38. 